\title{
DA UNASUL PARA O PROSUL: A VISÃO DO ESTADO DE DIREITO E O REGIONALISMO LATINO-AMERICANO
}

\author{
FROM UNASUR TO PROSUR: THE VIEW OF THE RULE OF LAW AND THE \\ LATIN-AMERICAN REGIONALISM
}

DOI: http://dx.doi.org/10.5380/cg.v9i1.72773

Octávio Forti Neto'

\begin{abstract}
Resumo
As organizações regionais latino-americanas são numerosas e tendem a tratar de diversos temas. De forma a analisar um tema específico do regionalismo latino-americano, é importante trazer a questão da defesa do Estado de Direito. Isto foi presente na UNASUL e se mostra realidade no PROSUL. Assim sendo, o objetivo deste artigo é trazer a temática da qualidade democrática, dentro do viés do Estado de Direito, na retórica das organizações regionais com foco específico nos mecanismos institucionais da UNASUL e, mais recentemente, no PROSUL. Através de estudos de caso, bem como entrevistas com oficiais dos países membros que participaram da UNASUL, pretende-se mostrar que o regionalismo Sul-americano sofre de deficiências, tais como: forte intergovernamentalismo, falta de resultados e propensão ideológica, que acabam por serem impeditivos para o fortalecimento do Estado de Direito.
\end{abstract}

Palavras-Chave: UNASUL; PROSUL; regionalismo sul-americano; Estado de Direito.

\begin{abstract}
Latin American regional organizations are numerous and tend to address several issues. To analyze a specific aspect of South American regionalism, it is important to bring the thematic of the defense of the rule of law. This was present at UNASUR and is a reality in PROSUR. Therefore, the objective of this article is to bring the theme of quality of democracy, within the rule of law, in the rhetoric of regional organizations with a specific focus on UNASUR's institutional mechanisms and, more recently, on PROSUR. Through case studies, as well as interviews with the actors, it is intended to show that South American regionalism suffers from deficiencies, such as strong intergovernmentalism, lack of results, and ideological propensity, which are impediments to the strengthening of the rule of law.
\end{abstract}

Keywords: UNASUR. PROSUR; South American regionalism; Rule of law.

\section{INTRODUÇÃO}

As organizações regionais na América Latina são numerosas. Há uma diversidade de estudos sobre o regionalismo no continente e suas diferentes nuances. De forma específica, a América do Sul tem passado por transições em termos de organizações regionais (ORs). Antes fortalecida, a União das Nações Sul-Americanas (UNASUL) acabou por definhar definitivamente em 2019, e uma nova

\footnotetext{
${ }^{1}$ Professor no Centro Universitário do Vale do Ribeira e Diretor de desenvolvimento econômico, ciência, tecnologia e Inovação do município de Registro-SP. E-mail: octaviofortineto@gmail.com. ORCID: http://orcid.org/oooo-0002-4452-838X.
} 
proposta de organização nasceu para suprir os interesses dos novos governantes, em sua maioria de direita, eleitos recentemente.

O Fórum para o Progresso da América do Sul (PROSUL) passa a ser um produto de um momento de acirramento ideológico na UNASUL em que desconectou países com diferentes alinhamentos ideológicos, que, em momentos anteriores, ainda se sentavam à mesa para discutir diferentes temas. Uma fala comum tanto na UNASUL quanto no PROSUL é que a democracia e, sobretudo, o Estado de Direito é algo a ser assegurado na América do Sul.

Nesse sentido, este artigo tem como objetivo trazer a temática da qualidade democrática, dentro do viés do Estado de Direito, na retórica das organizações regionais com foco específico nos mecanismos institucionais da UNASUL e, mais recentemente, no PROSUL. De forma simples, pretende-se buscar o entendimento dos atores e da institucionalidade regionais acerca da relação fortalecimento do Estado de Direito e regionalismo.

Este artigo usa como metodologia os estudos de caso da UNASUL e do PROSUL. Além da análise documental de ambas ORs, foram feitas 10 entrevistas com oficiais dos países membros da UNASUL, sendo embaixadores e técnicos que tiveram participação nas reuniões desta organização regional e funcionários da própria UNASUL. A ideia é estabelecer um breve processo comparativo das ações voltadas para o Estado de Direito da UNASUL e do PROSUL que no final das contas são muito similares. Apesar de o PROSUL ainda estar em estado inicial.

Assim, os atores regionais entendem que as ORs podem fomentar a qualidade democrática de seus países, sobretudo valorizando ações no Estado de Direito voltado para o combate à criminalidade e ações contra a violência, mas há muitas barreiras que o próprio regionalismo latinoamericano não permite desenvolver. O resultado principal é que as ORs produzem muito em termos de documentos, mas conseguem operacionalizar bem pouco. Nessa lógica, evidencia-se que o PROSUL, em seu início, segue o mesmo parâmetro institucional da UNASUL, um período de desenvolvimento de suas instituições com a criação de mecanismos para combater ações que desestabilizem o Estado de Direito, mas a história ainda tem muito por mostrar a partir de suas ações iniciais.

Este artigo também vai mostrar que o aspecto fortemente intergovernamental do regionalismo latino-americano, o vazio em procedimentos para atingir resultados e o aspecto ideológico de seus fundadores são impedimentos que colocam um "prazo de validade” em qualquer iniciativa regional latino-americana e, consequentemente, obstáculos para avançar em melhor qualidade democrática.

Este trabalho se divide em quatro seções. Primeiro será feito uma análise do regionalismo com vistas à América Latina. Após isto, considerações sobre o entendimento de consolidação e qualidade democráticas com foco no Estado de Direito. Em seguida a discussão sobre a metodologia usada e a análise da UNASUL e do PROSUL. 


\section{BREVES CONSIDERAÇÕES SOBRE O REGIONALISMO LATINO-AMERICANO}

O regionalismo é um termo que há tempos vem sendo utilizado para especificar processos de integração não somente na Europa, mas em todo mundo. Um dos aspectos fundamentais para entender o conceito de regionalismo é a questão da proximidade geográfica entre os Estados. De forma a corroborar esta afirmação, este artigo cita Nye (1968), o qual entende o termo como o "número limitado de estados vinculados por uma relação geográfica e por um grau de interdependência mútua" (p.vii, tradução livre)².

Dentro de uma abordagem mais recente nos estudos sobre regionalismo, Farrell (2005) tende a colocar o termo dentro de uma lógica de construção e reconstrução, conforme as mudanças no cenário internacional. Assim explica o autor: “[...] a região não é uma forma estática, mas dinâmica em seu desenvolvimento e aberta a mudanças e adaptação” (p. 8, tradução livre) ${ }^{3}$ O regionalismo deve ser entendido como uma forma multidimensional de integração, na qual abarca aspectos econômicos, sociais e políticos dos membros envolvidos.

Além disso, a maneira pela qual se constrói o regionalismo é inerente a cada região, não havendo padronização, pois o que o formará é oriundo das forças internas representadas pelos Estados (FARRELL, 2005). O regionalismo envolve não somente atores estatais, mas também não estatais, os quais se inserem na dinâmica própria de cada região.

Partindo do mesmo ponto de vista, Fawcett (2005) indica que o conceito de regionalismo tem sido flexibilizado ao longo da história. Antes apenas vinculado ao aspecto geográfico, baseado nas atitudes e preferência dos Estados, para além disso, a autora explica que regionalismo deve ser visto “[...] como uma política e um projeto pelo qual estados e atores não estatais cooperam e coordenam a estratégia dentro de uma determinada região" (tradução livre, p. 24)4.

Hurrell (2005), no mesmo sentido que os autores supracitados, aponta que pensar em uma lógica geral para o regionalismo é complexo, visto que cada região possui características próprias e, acima de tudo, dinâmicas próprias. Além disso, as regiões, ainda mais em um mundo globalizado, não são estáveis. Isto é, há sempre um elemento de instabilidade que retira o "status quo" de uma dada região. Ainda para o autor, saindo do escopo europeu, em que muitas das teorias foram construídas, pensar o regionalismo fora da dimensão europeia é complexo, levando a estudos regionais mais específicos.

Partindo dos pressupostos discutidos no item anterior, como entender o regionalismo latinoamericano? Malamud (2010) cita que a interação regional é uma prática comum entre as autoridades

\footnotetext{
2 Versão original: "limited number of states linked together by a geographic relationship and by a degree of mutual interdependence".

3 Versão original: "[...] the region is not a static form, but dynamic in its development and open to change and adaptation".

4 Versão original: “[...] as a policy and project whereby states and non-state actors cooperate and coordinate strategy within a given region".
} 
políticas no continente e que, historicamente, a região passou por diferentes ondas regionais. Estas ondas regionais são produtos históricos de convergência e divergência entre os Estados da região (DABENE, 2009). Além disso, Malamud (2010) aponta que o regionalismo latino-americano possui ações cruciais de seus presidentes na sua alavancagem, como também processos institucionais precoces e politização do processo integracionista. Isso será evidenciado na parte empírica deste artigo.

Nesse sentido, de forma a situar o processo histórico regional latino americano, apresentase, a seguir, no Quadro I, as ondas regionais que se desenvolveram ao longo dos anos.

\begin{tabular}{|c|c|c|}
\hline Onda & Característica & Exemplos \\
\hline $1^{\mathrm{a}}$ & $\begin{array}{l}\text { - Pós II Guerra Mundial; } \\
\text { - Interação Econômica; } \\
\text { - Alinhamento ao consenso de } \\
\text { Washington. }\end{array}$ & 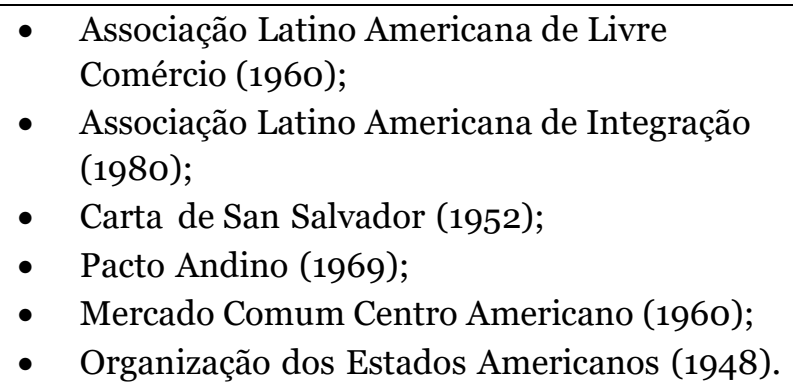 \\
\hline $2^{\mathrm{a}}$ & $\begin{array}{l}\text { - } \quad \text { Anos de 1990; } \\
\text { - } \quad \text { Regionalismo aberto; } \\
\text { - Liberalização econômica; } \\
\text { - Reformas de mercado; } \\
\text { - } \quad \text { Privatizações; } \\
\text { - } \quad \text { Esforços políticos para a consolidação } \\
\text { do processo de integração econômica; } \\
\text { - }\end{array}$ & $\begin{array}{l}\text { - } \quad \text { Mercado Comum do Sul (1991); } \\
\text { - } \quad \text { Comunidade Andina (1979); } \\
\text { - Área de Livre Comércio das Américas (não } \\
\text { concretizada); } \\
\text { - Sistema de Integração Centro Americano } \\
\text { (1991); } \\
\text { - Tratado Norte Americano de Livre Comércio } \\
\text { (1989) } \\
\text { - Clube do Rio (1986). }\end{array}$ \\
\hline $3^{o}$ & $\begin{array}{l}\text { - } \\
\text { - } \quad \text { Pós-liberal, pós-hegemônico ou pós- } \\
\text { neoliberal; } \\
\text { - } \quad \text { Retorno das relações políticas e sociais } \\
\text { entre os Estados; } \\
\text { - Identidade regional; } \\
\text { - Integração: } \\
\quad \text { Infraestrutura, segurança e defesa, } \\
\quad \text { produtiva, governança democrática, } \\
\text { segurança pública, etc; }\end{array}$ & $\begin{array}{l}\text { - Comunidade Sul Americana de Nações } \\
\text { (2004); } \\
\text { - União das Nações Sul-Americanas (2008); } \\
\text { - Comunidade dos Estados Latino-Americanos } \\
\text { e Caribenhos (2010); } \\
\text { - Aliança dos Povos para Nossa América } \\
\text { (2004). }\end{array}$ \\
\hline
\end{tabular}

Fonte: Elaboração própria, com base em Serbín (2013), Heine (2012), Rigirozzi e Tussie (2012) e Malamud (2013).

Malamud (2013), acerca da terceira onda regional, explica que elementos neofuncionais, como convergência de interesses, são rejeitados a favor de aspectos ideológicos. No entanto, é importante expor que elementos econômicos sobrepõem, muitas vezes, os próprios aspectos ideológicos, levando a que Dabene (2009) explicita como instrumentalização do regionalismo latinoamericano ora pendendo para aspectos econômico, ora para políticos. 
A partir da troca de governos de orientação ideológica mais à direita na América Latina nos últimos anos, as organizações regionais passaram a priorizar outras ORs voltadas para a economia, como a Aliança do Pacífico. Na América do Sul, a UNASUL, após 10 anos de funcionamento formal, foi esvaziada e os países acabam por formalizar a criação do Fórum de Progresso para a América do Sul (PROSUL).

Enfim, são dois os pontos que este artigo pretende frisar sobre o regionalismo na América do Sul: o primeiro deles é o vácuo entre objetivos, meios (métodos) e resultados, ou seja, visualiza-se um "gap" entre os discursos políticos, a forma com que se concretizam na prática e, sobretudo, a apresentação da efetividade dos processos regionais (DABENE, 2009); o segundo ponto é que as organizações latino-americanas são criadas para objetivos específicos, a fim de preencher os interesses pragmáticos dos Estados (NOLTE, 2014). Esses dois pontos serão evidenciados nas análises abaixo.

\section{A RELAÇÃo CONSOLIDAÇÃO/QUALIDADE DE DEMOCRACIA E ESTADO DE DIREITO}

Há diversos autores que tentam classificar as democracias latino-americanas, tais como, democracias jovens, iliberais, imperfeitas, anocracias, autoritarismo eleitoral, entre outros termos que caracterizam regimes híbridos, presente nas pesquisas sobre o assunto (GUNTHER et al, 2001; DIAMOND, 1999; O’DONNELL, 2001; SCHEDLER, 2001, entre outros). A classificação dos regimes democráticos ou, mesmo, autoritários já se arrasta por algumas décadas. Após a terceira onda de democratização na América Latina, as pesquisas têm se concentrado em três caminhos bem distinguíveis: os "transitologistas"; os "consolidologistas"; e os estudos preocupados com a qualidade de democracia ou seu aprofundamento.

Os transitologistas, mais comuns na década de 1980 e início dos anos de 1990, preocupavamse com os "reversals", ou seja, formas de evitar o retorno do autoritarismo. As pesquisas sobre consolidação democrática, feita pelos “consolidologistas”, especialmente na década de 1990, foram marcadas pelos diferentes debates acerca do que seria uma democracia consolidada, se era o tempo, a quantidade de eleições, o apelo aos direitos civis e políticos, a cultura política e o papel das massas, etc (SCHEDLER, 2001; LINZ; STEPAN, 1998; DIAMOND, 1999; entre outros).

Em meados dos anos 2000 até nossos dias, os estudos têm dado maior foco na qualidade da democracia ou seu aprofundamento (MUNCK, 2012; CHEIBUB, 2014; CORNELL, 2013; MORLINO, 2015). De fato, as discussões dos consolidologistas evoluíram a ponto de que os regimes são existentes e se denominam democráticos, mas qual qualidade de democracia está presente neles?

No que se refere à qualidade democrática, o foco tem sido, conforme Diamond e Morlino (2004) e Morlino (2015), na qualidade das instituições democráticas em manter a liberdade, a 
igualdade política e o controle sobre as políticas públicas e dos "policy makers". Na realidade, este artigo entende que o conceito de consolidação democrática é nebuloso e, mesmo, polissêmico (O’DONNELL, 2001). Similar ao termo democracia, a escolha de uma definição para consolidação possui desde vertentes minimalistas até as maximalistas 5 .

Neste sentido, as democracias passaram por um período de consolidação, principalmente nos anos posteriores as suas transições e hoje, como alguns autores apontam, há baixos riscos de "reversals" ou, mesmo, a possibilidade de golpes virem a tornar o regime autoritário (SLOVIK, 2014). Certamente, as probabilidades de tomada de poder em regimes presidencialistas ainda são razoáveis comparadas as de regimes parlamentaristas.

Schedler (2001) entende o termo consolidação democrática, a partir de cinco noções, as quais envolvem: impedimento de ruptura democrática; impedimento de erosão democrática; institucionalização da democracia; democracia completa; e, aprofundamento da democracia. As duas primeiras noções são consideradas, pelo autor, como negativas, uma vez que estão voltados para a defesa da democracia - evitar o retorno do autoritarismo -, já as duas últimas estão diretamente relacionadas com o aspecto positivo, visto que são voltadas fundamentalmente para a melhoria do grau de democracia. Nestes dois últimos, os estudos sobre qualidade da democracia são mais significantes.

A qualidade de democracia se torna importante uma vez que ela pode estar atrelada à democracia completa ou, mesmo, ao aprofundamento da democracia. Morlino (2015) explica que a qualidade estaria na efetividade das instituições em permitir que a constituição funcione e resolva conflitos dentro da democracia, permita a participação ampla dos interessados, regulamente a competição eleitoral entre os partidos, julgue todos de maneira igual e possua/tenha mecanismos de monitoramento entre as instituições.

O que se evidencia é que o Estado de Direito tem sido considerado a base para que os cidadãos possam usufruir de suas liberdades. É através do Estado que há a promoção das leis e dos direitos, como também o gerenciamento e a eficácia da constituição (MORLINO, 2015). Por isso, a reafirmação do Estado de Direito é, de fato, base fundamental para que outros aspectos da qualidade da democracia funcionem (FORTI NETO, 2019).

Dessa forma, Morlino (2015) tem pautado seus estudos em algumas dimensões, as quais abarcam uma variedade de temas. Para o autor, tais dimensões podem também ser transferidas para um nível analítico além dos Estados, como o supranacional. O que este artigo vai considerar é que o Estado de Direito é um fator basilar para que outros aspectos da qualidade de democracia sejam analisados. Assim, Estado de Direito envolve a supremacia da lei e a capacidade do Estado em fazer

\footnotetext{
$5 \mathrm{O}$ termo minimalista ou maximalista foi encontrado nos escritos de Gunther et al (2001). Da mesma forma, é possível mergulhar na discussão sobre o conceito de democracia, o qual pode também abarcar aspectos minimalistas, como as definições de Schumpeter, e até mesmo procedimentais como as de Dahl, entre diversos outros autores com diferentes dimensões sobre a democracia.
} 
valer e respeitar suas instituições. Além disso, deve fazer valer a independência do judiciário e o controle civil sobre seu próprio exército (MORLINO, 2015).

Há uma variedade de temas que envolve o Estado de Direito, os quais o Quadro II mostra abaixo:

QUADRO II - ITENS DA DIMENSÃO DO ESTADO DE DIREITO DE MORLINO (2015).

\begin{tabular}{l}
\hline $\begin{array}{l}\text { Segurança individual e ordem civil com foco em direito à vida, ausência do medo e da tortura, segurança } \\
\text { pessoal e o direito à propriedade privada; }\end{array}$ \\
\hline $\begin{array}{l}\text { A aplicação erga omnes do sistema jurídico, também no nível supranacional, garantindo os direitos e a } \\
\text { igualdade dos cidadãos; }\end{array}$ \\
\hline A ausência, mesmo em nível local, de áreas dominadas pelo crime organizado; \\
\hline A existência de uma burocracia, local, centralizada e civil que competente e eficientemente aplica as leis; \\
\hline A existência de uma força policial eficiente que respeita os direitos e liberdades garantidas pela lei; \\
\hline Acesso igualitário e desimpedido de cidadãos ao sistema de justiça em casos de processos; \\
\hline Resolução razoavelmente rápida de investigações criminais e de processos judiciais; \\
\hline A completa independência do Judiciário de qualquer influência política; \\
\hline A ausência de corrupção nos poderes político, administrativo e judiciário. \\
\hline
\end{tabular}
Fonte: Morlino (2015, p.182).

Por fim, infere-se que um dos elementos mais importantes que as ORs têm trazido para a discussão da democracia é que elas podem fortalecer o Estado de Direito (FORTI NETO, 2019). Certamente, não é possível que as ORs possam atingir os elementos do Quadro II em sua totalidade, mas há evidências que a UNASUL buscou isso ao longo de seus anos de existência, sobretudo, ao pensar na construção institucional de seus conselhos.

\section{CONSIDERAÇÕES METODOLÓGICAS}

O foco aqui é o estudo de caso. Yin (2002) acredita que o estudo de caso envolve fenômenos contemporâneos, cujas variáveis são pouco controláveis pelo investigador. Merriam (1998), por sua vez, explica que estudo de caso é um sistema limitado e, ao mesmo tempo, integrado. Vennesson (2008) ao citar Ragin, expõe que um estudo de caso é uma estratégia importante de pesquisa voltado para investigação empírica aprofundada "de um, ou um pequeno número de fenômenos, a fim de explorar a configuração de cada caso e elucidar características de uma classe maior de fenômenos (semelhantes), desenvolvendo e avaliando explicações teóricas" (tradução livre, p.226)6.

Além disso, aplicou-se 10 entrevistas (virtuais e por questionários) a partir de questões semiestruturadas abertas, variando de 10 a 12 questões, a diferentes funcionários governamentais (embaixadores, coordenadores e técnicos) da UNASUL. A todos eles foram feitos as seguintes

\footnotetext{
${ }^{6}$ Versão original: "of one, or a small number, of phenomena in order to explore the configuration of each case, and to elucidate feautures of a larger class of (similar) phenomena, by developing and evaluating theoretical explanations".
} 
perguntas: Você acredita que a UNASUL pode promover consolidação democrática através do fortalecimento do Estado de Direito? O que você faria para melhorar a efetividade da UNASUL em promover consolidação ou qualificação democrática? Você acredita que as ações da UNASUL atingem ao âmbito doméstico dos países? Todas as entrevistas foram feitas entre os anos de $2018 \mathrm{e}$ 2019. Os documentos analisados foram os tratados constitutivos de ambas ORs, relatórios produzidos por alguns dos conselhos da UNASUL, como os de segurança cidadã e o de mundial de combate as drogas. Além disso, documentos anteriores ao surgimento da UNASUL, como o da Comunidade Sul-Americana de Nações.

Este artigo buscou triangular, como critério de validação e, ao mesmo tempo, de confiabilidade a pesquisa, os documentos analisados das ORs e parceiras, pesquisas realizadas com os dados coletados, sobretudo, das entrevistas e os aspectos teóricos supramencionados. A triangulação busca diminuir as inconsistências e possíveis contradições dentro de uma pesquisa científica (YIN, 2002; GASKELL; BAUER, 2005). A triangulação é um critério muito importante para a pesquisa qualitativa, pois permite ao pesquisador trabalhar com diferentes fontes de dados e informações de maneira a convergi-los e sistematizá-los na análise de um mesmo fenômeno (YIN, 2002).

Em geral Kirk e Miller (1986) apontam que validade é referente à fidelidade com seus objetivos, isto é, validade aparente (método de pesquisa produz o resultado desejado), validade instrumental (métodos utilizados) e validade teórica (legitimidade dos termos da pesquisa). A confiabilidade, de acordo com os mesmos autores, refere-se que outros pesquisadores possam chegar a resultados semelhantes ao que o pesquisador chegou. Assim, as circunstâncias são analisadas, observação através do tempo e a busca por similaridades na observação. Este artigo buscou seguir esses pressupostos, a partir da lógica de que o Estudo de caso pode ser replicado para outros casos.

\section{CASOS DA UNASUL E DO PROSUL}

\subsection{BREVE HISTÓRICO DOCUMENTAL DA COMUNIDADE SUL-AMERICANA DE NAÇÕES (CSN) E DA UNASUL}

A conformação histórica da UNASUL é fundamental para o entendimento da lógica do Estado de Direito construída na OR. Inclusive Forti Neto (2019) expõe que não apenas na UNASUL, mas também em outras ORs, como no Sistema de Integração da América Central (SICA), o Estado de Direito tem papel fundamental no regionalismo. Nesse sentido, entre os anos de 2000 e 2002 foram realizadas duas reuniões de presidente sul-americanos. A primeira vez em que chefes de Estado de toda a região sul-americana estiveram reunidos para discutir problemas nacionais e regionais ocorreu em 2000 (FARIA; TANCREDI, 2015). A segunda e terceira reuniões geraram a Declaração 
de Guayaquil (CLAES, 2002) e Declaração de Cuzco (CSN, 2004). Nesta última os presidentes concretizam a CSN. Faria e Tancredi (2015) explicam que a CSN foi o primeiro mecanismo de coordenação política da América do Sul. A organização nasceu como um "transcendental consenso político" dos presidentes de maioria de esquerda do período (RUVALCABA; VALENCIA, 2012).

Entre 2004 a 2007, a CSN formalizou três reuniões - 2005, 2006 e 2007. A primeira - em 2005 - focou em aspectos institucionais, burocráticos e esforços para associar o MERCOSUL e a Comunidade Andina, como também a criação de uma agenda prioritária. Já a segunda reunião Declaração de Cochabamba (CSN, 2006) - tratou de diversos temas, abarcando a democracia, direitos humanos, indústria, economia, comércio, identidade, paz, pobreza, participação, infraestrutura, entre tantos outros. A institucionalidade hierárquica regional foi desenhada para não sobrepor esforços entre as instituições regionais.

Na Declaração de Margarita (CSN, 2007) foi alterado o nome de Comunidade para União das Nações Sul-Americanas com sede da secretaria permanente em Quito. A Iniciativa para Integração da Infraestrutura Regional Sul-Americana (IIRSA) foi um motor importante para a integração tanto no período que antecedeu quanto durante a existência da CSN (2000-2007). Contudo, as negociações da ALCA e as guinadas dos governos de centro-esquerda e esquerda na região trouxeram para a UNASUL temas sociais e culturais embutidos nas discussões (NERY, 2016). Havia convergência dos países sul-americanos trazendo os atores para o diálogo.

Em maio de 2008 foi aprovado seu Tratado Constitutivo (UNASUL, 2008), confirmando a sua sede em Quito (Equador) e o Parlamento em Cochabamba. A vigência do tratado passou a ocorrer a partir de 11 de março de 2011. Ruvalcaba e Valencia (2012) explicam que o tratado constitutivo institucionalizou o que estava acontecendo na região há pelo menos 15 anos de maneira informal. A partir de 2008, a OR obteve sua personalidade jurídica, normas, estatutos e conselhos setoriais específicos.

A UNASUL teve seus momentos de grande relevância na região. Ela atuou em diversos acontecimentos, tais como, terremoto do Haiti (2010)7, crise boliviana ${ }^{8}$ de 2008 , rechaço à criminalização de imigrantes, a partir da diretiva da União Europeia, nomeação do primeiro secretário geral da UNASUL (ex-presidente chilena Michelle Bachelet), pronunciamentos sobre o golpe de Honduras de 2009, a situação do Equador (2010) ${ }^{9}$, entre outras ações da organização regional (RUVALCABA; VALENCIA, 2012).

\footnotetext{
7 Documento Solidariedad de Unasur com Haití: decisión de Quito 09/02/2010. Disponível em: http://www.itamaraty.gov.br/images/ed integracao/docs UNASUL/DEC.2010.SOLHAITI.pdf. Acesso 07 jan. 2019.

8 Documento Declaración de la Moneda. 15/09/2008. Disponível em: http://www.itamaraty.gov.br/images/ed integracao/docs UNASUL/DECL.2008.LAMONEDA.pdf. Acesso 07 jan. 2019.

9 Documento Delcaración de Buenos Aires sobre la situación de Ecuador. 01/10/2010. Disponível em: http://www.itamaraty.gov.br/images/ed integracao/docs_UNASUL/DECL.2010.EQUAD.pdf. Acesso 07 jan. 2019.
} 
5.1.1. UNASUL e a questão do Estado de Direito: uma análise de seus documentos e entrevistas

No Tratado Constitutivo da UNASUL (2008), tanto o preâmbulo quanto o seu objetivo principal trazem a temática do fortalecimento da institucionalidade democrática. No protocolo adicional de 2010, que entrou em vigor em 2014, o conteúdo trata de diversos pontos sobre o compromisso com a democracia, entre eles a vigência das instituições democráticas e medidas que visam a proteção da ordem e da institucionalidade democrática. Assim, no preâmbulo constata-se o compromisso com o Estado de Direito e com a democracia:

Reiterando nosso compromisso com a promoção, defesa e proteção da ordem democrática, do Estado de Direito e suas instituições, dos direitos humanos e as liberdades fundamentais, incluindo a liberdade de opinião e de expressão, como condições essenciais e indispensáveis para o desenvolvimento de seu processo de integração, e requisito essencial para sua participação na UNASUL.

Nota-se que no artigo 3 do Tratado Constitutivo (UNASUL, 2008) - nos incisos do "q" ao "u” dos objetivos específicos - a temática da segurança cidadã e temas relativos ao Quadro III sobre Estado de Direito de Morlino (2015) estão presentes.

QUADRO III -INCISOS DOS OBJETIVOS ESPECÍFICOS SOBRE O ESTADO DE DIREITO

\begin{tabular}{|c|l|}
\hline Inciso & \multicolumn{1}{c|}{ Temática do Estado de Direito } \\
\hline Q & $\begin{array}{l}\text { A coordenação entre os organismos especializados dos Estados-Membros, levando em conta as } \\
\text { normas internacionais, para fortalecer a luta contra o terrorismo, a corrupção, o problema mundial } \\
\text { das drogas, o tráfico de pessoas, o tráfico de armas pequenas e leves, o crime organizado } \\
\text { transnacional e outras armas, assim como para promover o desarmamento, a não proliferação de } \\
\text { armas nucleares e de destruição em massa e a desminagem; }\end{array}$ \\
\hline R & A promoção da cooperação entre as autoridades judiciais dos Estados-Membros da UNASUL; \\
\hline S & O intercâmbio de informação e de experiências em matéria de defesa; \\
\hline T & A cooperação para o fortalecimento da segurança cidadã, e; \\
\hline U & $\begin{array}{l}\text { A cooperação setorial como um mecanismo de aprofundamento da integração sul-americana, } \\
\text { mediante o intercâmbio de informação, experiências e capacitação. }\end{array}$ \\
\hline
\end{tabular}

Fonte: UNASUL (2008).

Ainda na temática, a UNASUL desenvolveu dentro de sua institucionalidade conselhos ministeriais de trabalho que pudessem atuar no combate às drogas e aspectos voltados para a segurança cidadã de forma a fortalecer o Estado de Direito de seus membros. O Conselho Sulamericano de Prevenção ao Problema Mundial das Drogas (CSPMD) - criada em agosto de 2009 e o Conselho Sul-Americano de Segurança Cidadã, Justiça e Delinquência Organizada Transnacional (CSSJDOT) - a partir de novembro de 2012 - são exemplos nesta linha. Eram os únicos conselhos que, de fato, partiam para uma lógica voltada para a defesa do Estado de Direito (FORTI NETO, 2019).

Os objetivos de ambos os conselhos estavam voltados para os aspectos presentes em Morlino (2015) no Quadro II deste artigo. Por exemplo, o CSSJDOT tinha em seu estatuto (2012, art 3, inciso 
h) que o seu objetivo era “[p]romover o fortalecimento das instituições governamentais encarregadas da segurança cidadã, da justiça e da ação contra o crime organizado transnacional, de acordo com os princípios constitucionais e as disposições normativas de cada Estado membro" ${ }^{10}$, bem como o "Respeito irrestrito aos direitos humanos, as liberdades e garantias fundamentais dos cidadãos, em um marco de plena vigência das instituições democráticas”"11 (CSSCJDOT, 2012, art. 2, inc. C, tradução livre). Na análise das entrevistas, que ocorreram entre os anos de 2018 e 2019, os atores foram bem claros sobre a UNASUL.

Um entrevistado do alto escalão do Ministério das Relações Exteriores do Brasil (2018) respondeu que boas práticas podem ser importantes em um processo regional, mas depende muito do país recipiendário, pois atinge diretamente o ordenamento interno legislativo e constitucional. No caso da UNASUL, ele expôs “[n]ão creio que a UNASUL tenha estrutura e capacidade política para disseminar as práticas [...]. Haveria, no máximo, uma aproximação inicial, que dependeria, para ter efetividade, do engajamento bilateral com os países que se demonstrassem interessados". No geral, o oficial expõe que qualquer medida da UNASUL para manutenção do Estado de Direito não teria efeitos deletérios econômico e sociais, principalmente nos últimos anos com seu declínio. Ele complementa:

\begin{abstract}
A UNASUL permanece, nesse campo, um foro de ressonância de discursos políticoideológicos nacionais, mas não vai além do nível do discurso. Não se trata, aqui, de uma crítica dirigida ao modo como a UNASUL foi constituída, mas à impossibilidade política de obter convergências efetivas entre países com históricos e posicionamentos ideológicos tão díspares, por vezes antagônicos, como os países sulamericanos.
\end{abstract}

Por fim, o mesmo entrevistado aponta que consolidar a democracia é algo particular de processos históricos de cada país. A UNASUL não teria a função de ser "bedel” da democracia. Para ele, há outras pautas mais prioritárias e que não é a vocação da OR entrar neste quesito de consolidação.

Um embaixador colombiano (2018), o qual participou em muitas reuniões dos conselhos da UNASUL, apresentou que as sociedades não possuem um comum entendimento do Estado de Direito. O que parece, na visão dele, que a "UNASUL poderia ajudar na construção de nossa identidade sul-americana antes de promover o fortalecimento do Estado de Direito" ${ }^{12}$. Para o embaixador, uma forma de melhorar a democracia na América do Sul pela UNASUL seria tornar as

\footnotetext{
${ }^{10}$ Versão original: "Promover el fortalecimiento de las instituciones gubernamentales encargadas de la seguridad ciudadana, la justicia y el accionar en contra de la Delincuencia Organizada Transnacional, bajo los principios constitucionales y disposiciones normativas de cada Estado miembro".

11. Versão original: "Respeto irrestricto a los derechos humanos, las libertades y garantías fundamentales de los ciudadanos, en un marco de plena vigencia de las instituciones democráticas".

${ }_{12}$ Versão original "Unasur podría ayudar en la construcción de nuestra identidad suramericana antes de promover el fortalecimiento del Estado de Derecho".
} 
decisões governamentais, isto é, as leis pautadas em evidências científicas. Conforme ele, "Muitos delegados vão com uma bagagem ideológica muito grande e pouca evidência científica"13.

Outro oficial de alto escalão no Ministério das Relações Exteriores do Peru (2018) expõe que o Estado de Direito é fundamental para que haja equilíbrio de poderes. O grande problema da UNASUL, segundo ele, é que as decisões não são vinculantes. Ele acredita que as experiências e as boas práticas são importantes para resolver problemas comuns na UNASUL. No caso, naquele período, a UNASUL precisava diminuir suas cargas ideológicas para decisões mais técnicas para o bem comum. Esta era a mesma visão da maioria dos entrevistados.

O diretor de segurança cidadã da UNASUL (2018) apresentou que a OR permite o diálogo entre os países, ajudando em problemas regionais comuns. Isso ocorre na mesma lógica da melhoria da democracia, pois há trocas de experiências. Para ele, a UNASUL, como instituição, seria um problema para consolidar ou qualificar as democracias, pois a "[...] secretaria geral tem pouca articulação e pouco controle da situação. O conselho não via a secretaria geral como sócio estratégico. Em geral, não há mecanismos que permitam que os projetos sigam a diante" (tradução livre) ${ }^{14}$.

Outro Oficial de alto escalão do MRE da Guiana (2019) apresentou que "[d]esde que a lei e a ordem continuam a ser um grande desafio para a maioria, se não todos, os países sul-americanos, os mecanismos estabelecidos pela UNASUL podem fazer grande parte do processo de consolidação democrática e também ajudar no fortalecimento das instituições nacionais" ${ }^{15}$. Para o oficial, a UNASUL deveria dialogar mais para que possa trocar experiências e consolidar suas democracias focadas em problemas comuns.

Um oficial do Peru, coordenador da UNASUL em seu país, foi o que mais entendia sobre Estado de Direito e democracia. Ele fez uma longa explicação sobre o que entendia sobre os termos em muitos aspectos coerentes com o Quadro II e, após isso, disse:

Sendo assim [...] as ações, decisões e intenções da UNASUL estão encaminhadas ou orientadas precisamente ao fortalecimento do Estado de Direito e, consequentemente, à consolidação democrática, no entendimento que, esta última, só é possível alcançar através do desenvolvimento do primeiro ${ }^{16}$.

\footnotetext{
${ }_{13}$ Versão original: "Muchos delegados vienen con una carga ideológica muy grande y poca evidencia científica".

14 Versão original: "El secretario general tiene poca articulación y poco control de la situación. La junta no vio al secretario general como un socio estratégico. En general, no existen mecanismos que permitan que los proyectos avancen".

15 Versão original: "Since law and order continues to be a big challenge for most if not all of South America, the mechanisms established by UNASUR can play a big part to consolidate democratic processes and also help the strengthen national institutions".

16 Versão original: "Siendo así y conforme a lo explicado anteriormente, las acciones, decisiones e intenciones de la UNASUR están encaminadas u orientadas precisamente al fortalecimiento del Estado de Derecho y, consecuentemente, a la consolidación democrática, en el entendido que, esta última, solo es posible alcanzarla a través del desarrollo del primero".
} 
Para ele, a UNASUL precisava superar sua crise para mostrar resultados. Buscar ações que fizessem um diagnóstico regional com os problemas e formas de consolidar e qualificar melhor as democracias. Assim, tendo conhecimento dos problemas e dificuldades dos países, "[...] desenhar estratégias conjuntas e planos de ação orientados a alcançar a melhor solução nas diferentes áreas temáticas nas que atuam no CSSCJDOT, seguindo como norte o fortalecimento do Estado de Direito e a consolidação democrática" ${ }^{17}$.

Um oficial do Brasil (2018), no período era do Ministério da Justiça, que também participou de muitas reuniões dos conselhos, explicitou que a UNASUL não avançou em consolidação democrática porque o Brasil não quis colocar isso como pauta. Ele participou do órgão em tempos de grande prestígio - no início - e no declínio. Para ele, se o Brasil quisesse naquele momento desenvolver pautas democráticas teria apoio dos países. Contudo, as mudanças ideológicas acabaram de enfraquecer os processos. Para ele, havia no período o grande problema da desintegração, como houve de fato. "[...] se for desinteresse coletivo em relação a desintegração e na defesa dos componentes específicos do Estado democrático de direito é esperar que a UNASUL acaba secando e saindo do ar".

Por fim, a embaixadora do Peru (2018) explica que a UNASUL poderia melhorar a governabilidade democrática, uma vez que todo o aspecto da criminalidade e drogas afeta o Estado de Direito. Para ela, a UNASUL só poderá fortalecer o Estado de Direito se tiver a liderança do Brasil neste processo, sem isso não há possibilidades de avanço. Embora a democracia seja uma condição sine qua non, ela acredita que o Brasil é a grande liderança, que passou a ter uma distância psicológica muito clara em relação ao bloco. Os embaixadores da Argentina (2018) e do Uruguaio (2019) também fizeram diversas considerações, mas o comum é que para trazer consolidação ou, mesmo qualidade democrática a UNASUL necessita de continuidade em seus processos e, principalmente, vontade política.

Importante trazer para este bojo de estudo, os escritos Luigi (2017), Nery (2016) e Forti Neto (2019), os quais se aprofundaram nos estudos da UNASUL e, de certa forma, convergem com o que os oficiais acima explicitaram. Interessante que esses estudos mostram que a OR, no seu período de existência, buscou incorporar as estruturas institucionais existentes de seus Estados na sua, como o caso da Saúde (LUIGI, 2017) e, mesmo, da segurança cidadã, (FORTI NETO, 2019). Mas como mostram estes autores, a questão da infraestrutura e dos recursos humanos foram grandes impeditivos de suas capacidades. Embora Luigi (2017) aponte que na área da Saúde havia instituições ligadas à UNASUL que possuíam trabalhos consistentes.

Ruvacalba e Valencia (2012) e Nery (2016) apontam que a UNASUL foi legítima em mediar conflitos, assumindo um papel mais preponderante que a própria Organização dos Estados

\footnotetext{
17 Versão original: “[...] diseñar estrategias conjuntas y planes de acción orientados a lograr la mejor solución en las diferentes áreas temática en las que actúa el CSSCJDOT, siguiendo como norte el fortalecimiento del Estado de Derecho y la consolidación democrática".
} 
Americanos. Como expôs a embaixadora peruana (2018), a UNASUL iria ser o que o Brasil quisesse que ela fosse, pois sem a liderança ela não persistiria e isso veio a se consolidar em 2019. O que autores como Luigi (2017), Forti Neto (2019) e outros apontam é que a OR teve seu período de desenvolvimento inicial entre 2008-2011, consolidou-se entre 2011-2015 e se estagnou entre 20162018. Sobre este último período, Luigi tenta ser menos fatalista ao expor que seria um período de latência "à espera de um novo ciclo de expansão da economia mundial/ regional, e no aguardo, minimamente, de continuidade das condições institucionais que havia e que se perderam [...]" (p.176). Com a guinada de governos de direita em meados dos anos 2010, a UNASUL não persistiu para um novo ciclo econômico.

Como mostrou a história, a OR vinha sofrendo com diversos problemas nos últimos anos. O aspecto ideológico tem sido a causa, de acordo com os atores envolvidos, para a estagnação e deterioração do bloco. O primeiro conflito relevante ocorreu em 2017 com a falta de um Secretário Geral, que gerou rusgas sobre a nomeação do Argentino Octávio Bordón. Venezuela, Bolívia e Equador não aceitaram e não apresentaram alternativas.

Diante do exposto acima, em abril de 2018, um grupo de países se afastou do bloco Argentina, Brasil, Paraguai, Chile, Peru e Colômbia. Ainda no segundo semestre daquele ano, a Colômbia oficializou sua saída. O esvaziamento foi confirmado em março de 2019 com a criação do PROSUL e a confirmação de que os países já suspensos do bloco formalizassem sua saída, como por exemplo, o Brasil e o Chile em 2019. A guinada dos governos de direita na América do Sul tem sido considerada fator chave para o esvaziamento da UNASUL.

\subsection{OS PRIMEIROS PASSOS DO PROSUL}

A Declaração de Santiago de 22 de março de 2019 é o primeiro documento do PROSUL (2019). O Quadro IV abaixo mostra de forma sintética os principais pontos do documento assinado pelos países, o qual teve como signatários Argentina, Brasil, Chile, Colômbia, Equador, Guiana, Paraguai e Peru.

QUADRO IV - PONTOS IMPORTANTES DA DECLARAÇÃO DE SANTIAGO (2019) [continua]

\begin{tabular}{|c|c|}
\hline Tópicos & Características \\
\hline Estrutura & Flexibilidade, simplificação, pragmatismo e não duplicidade institucional; \\
\hline Presidência & 12 meses (Chile); Sucessão (Paraguai). \\
\hline Temas & $\begin{array}{l}\text { - Infraestrutura; } \\
\text { - Energia; } \\
\text { - Saúde; } \\
\text { - } \quad \text { Defesa e segurança; } \\
\text { - } \quad \text { Pombate ao crime; } \\
\text { - } \quad \text { Desenenção de e resposta a desastres naturais. } \\
\text { - Eliminação da pobreza; }\end{array}$ \\
\hline
\end{tabular}


QUADRO IV - PONTOS IMPORTANTES DA DECLARAÇÃO DE SANTIAGO (2019) [conclusão]

\begin{tabular}{|l|l|}
\hline Temas & $\bullet$ Empreendedorismo. \\
\hline Soberania & $\bullet$ Integridade territorial; \\
& $\bullet$ Zona de Paz. \\
\hline Requisitos para participação & $\bullet \begin{array}{l}\text { Plena vigência da democracia e ordem constitucional; } \\
\text { humanos e das liberdades fundamentais. }\end{array}$ \\
\hline
\end{tabular}

Fonte: elaboração própria.

Os discursos presidenciais se mostram como um fórum de diálogo, sem ideologias, pragmático e que reúna toda a América do Sul. O mesmo contexto de construção da UNASUL. Aliás, os mesmos temas do Quadro acima também foram tratados na UNASUL, inclusive a ideia de integração em diferentes velocidades, tratando das realidades de cada Estado-parte. Havia também a ideia de aproveitar as estruturas do MERCOSUL e da CAN, como no atual PROSUL. A diferença é que naquele momento havia a ascensão da esquerda na região, bem como o contexto comum de lutar contra a ALCA.

5.2.1. PROSUL e a questão do Estado de Direito: uma análise inicial

Em setembro de 2019, os países do PROSUL se reuniram e acordaram uma cláusula democrática e de Estado de Direito a qual infere que para os países participarem da OR precisam atingir os seguintes objetivos (PROSUL, 2019a):

a) a vigência do Estado de Direito, da democracia representativa, das eleições livres e das respectivas ordens constitucionais;

b) a separação de poderes do Estado; e a sujeição das forças públicas à autoridade civil legalmente constituída;

c) a promoção, proteção, respeito e garantia dos direitos humanos e das liberdades fundamentais;

d) o respeito à soberania e à integridade territorial dos Estados, assim como ao direito internacional.

Além disso, o PROSUL tem em sua linha b dos objetivos o fortalecimento das liberdades e da democracia (PROSUL, 2019a). No preâmbulo se evidencia o seguinte aspecto neste mesmo sentido:

CONSIDERANDO sua vontade de criar um espaço para promover o desenvolvimento sustentável e inclusivo, o fortalecimento dos valores e princípios democráticos, o respeito ao direito internacional, ao Estado de Direito e aos direitos humanos que os países participantes compartilham, como garantias para a construção da paz e prosperidade econômica e social. ${ }^{18}$

18 Versão original: "CONSIDERANDO su voluntad de crear un espacio para promover el desarrollo sostenible, inclusivo y sustentable, el fortalecimiento de los valores y principios democráticos, el respeto al 
No mesmo preâmbulo é possível captar também mais uma citação ao Estado de Direito em que se coloca "a plena vigência da democracia, do Estado de Direito, das respectivas ordens constitucionais e a promoção, proteção, respeito e garantia dos direitos humanos e as liberdades fundamentais"19.

Ainda não se tem evidências claras sobre como vai se desenvolver a OR, mas desde seu surgimento em março de 2019 já houve mudanças eleitorais nos países envolvidos, por exemplo, a Argentina elegeu recentemente um governo de centro-esquerda, após o Macri não ter atingido as expectativas com seu governo.

Outro aspecto que o PROSUL tem se deparado e não houve reação foi a questão das crises que houve no Chile, na Bolívia, no Peru, no Equador. Um desafio que a UNASUL, entre os anos de 2008 a 2014, soube lidar e convergir diante das instabilidades que ocorreram no período (NERY, 2016). Talvez seja cedo demais para culpar a organização ou se é uma "organização", visto que o documento de setembro de 2019 já aponta para uma institucionalidade prevista.

\section{REFLEXÕES FINAIS: A BUSCA DE UM ENTENDIMENTO SOBRE AS ORS - UNASUL E PROSUL}

Diferentemente da UNASUL, o PROSUL surge em um contexto de contraposição ideológica a uma organização regional. Embora o presidente chileno Sebastián Piñera discurse que será "Um fórum sem ideologias, sem burocracias, franco e direto com democracia e direitos humanos"20, a ideia se apresenta como uma resposta da direita ao viés de esquerda da UNASUL e à Venezuela.

De fato, o que este artigo evidencia é que o PROSUL poderá ser mais uma OR latinoamericana fadada à estagnação em algum momento, sobretudo, com as mudanças ideológicas e as crises democráticas em muitos países da região. Como exposto no texto, os interesses pragmáticos dos estadistas criadores é que pautam as ações da OR. Contudo, são necessários mais estudos para aprofundamento em seus diferentes aspectos. Além disso, como relatado por quase todos os entrevistados, os aspectos ideológicos sobrepuseram muitas das decisões técnicas e, mesmos, as discussões na UNASUL, sendo a causa de seu esvaziamento. Pode se evidenciar isso no PROSUL, mesmo antes de sua consolidação no regionalismo latino-americano, especialmente com as falas dos presidentes chilenos e os comentários do estadista brasileiro.

derecho internacional, al Estado de Derecho y a los derechos humanos, que los Países Participantes comparten, como garantías para la construcción de la paz y prosperidad económica y social".

19 Versão original: "la plena vigência de la democracia, del Estado de derecho, de los respecticos órdenes constitucionales y la promoción, protección, respeto y garantía de los derechos humanos y las libertades fundamentales".

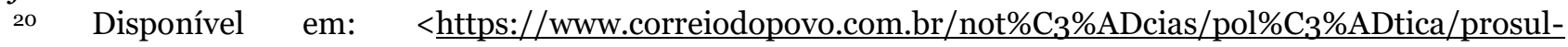
ser\%C3\%A1-um-f\%C3\%B3rum-sem-ideologias-defende-pi\%C3\%B1era-1.328289>. Acesso 25 abr. 2019. 
O tratamento dado a temática do Estado de Direito pela UNASUL e pelo PROSUL são muito similares em seus documentos. Contudo, como já exposto na primeira parte deste artigo, o regionalismo na América Sul e, mesmo, latina tendem a ter um "gap" entre os discursos políticos e a prática das ações ou um vazio entre os objetivos e resultados. A UNASUL não obteve grandes conquistas como mostrado.

Por fim, o Estado de Direito é um dos temas recorrentes que muitas ORs latino-americanas citam e tratam em suas constituições haja vista não apenas a UNASUL, como também o atual PROSUL. Além disso, o MERCOSUL, a CAN, o SICA entre diversas outras que surgiram na região tratam da temática. Elas explicitam muito a questão do ser democrático, da consolidação democrática, do fortalecimento do Estado de Direito, mas conseguem operacionalizar pouco em termos de resultados, sobretudo, pelos problemas ideológicos, no caso da UNASUL, mas também em termos de que o regionalismo latino-americano tem forte apelo intergovernamental não tendo decisões vinculantes nas decisões no âmbito regional ao doméstico. Nesse sentido, pela experiência da UNASUL, evidencia-se que o PROSUL pode seguir o mesmo caminho. Mais estudos são necessários para compreender e analisar a ascensão de governos de direita e a realidade regional sulamericana e, mesmo, como procederá o desenvolvimento institucional do PROSUL. Os próximos meses e anos darão maior subsídio para avanços nesse sentido.

*Artigo recebido em 13 de abril de 2020, aprovado em 01 de junho de 2020.

\section{REFERÊNCIAS}

CENTRO LATINO AMERICANO DE ECOLOGÍA SOCIAL (ClAES). Segunda Reunión de Presidentes de América del Sur 2002: Consenso de Guayaquil sobre Integración, seguridad e infraestructura para el desarrollo. Guayaquil, 26 e 27 de julho de 2002. Disponível em: <https://www.sciencespo.fr/opalc/sites/sciencespo.fr.opalc/files/Dcmaration_de_Guayaquil_20 02.pdf $>$. Acesso em 25 de fev. 2019.

CHEIBUB, J. A. The c onstitutional f oundations of d emocratic c onsolidation”. Comparative Democratization 12, $\mathrm{n}^{\circ}$ 2. 2014. p.7-10.

COMUNIDADE SUL-AMERICANA DE NAÇÕES (CSN). III Cumbre Sudamericana de Naciones: Declaración del Cusco sobre la Comunidad Sudamericana de Naciones. Cuzco, 8 de dezembro de 2004. Disponível em: <http://www.iirsa.org/admin_iirsa_web/Uploads/Documents/oe_cuscoo4_declaracion_del_cus co.pdf $>$. Acesso em 25 de fev. 2019.

COMUNIDADE SUL-AMERICANA DE NAÇÕES (CSN). Declaración de Cochabamba: colocando la Piedra Fundamental para una Unión Sudamericana. II Cumbre de Jefes de Estado de la Comunidad Sudamericana de Naciones. Cochabamba: 8 e 9 de dezembro de 2006. Disponível em: $<\quad$ http://walk.sela.org/attach/258/EDOCS/SRed/2010/o9/To23600004327-0- 
Declaracion de Cochabamba -

Colocando la Piedra Fundamental para una Union Sudamericana, 2006.pdf >. Acesso em 25 de fev. de 2019.

COMUNIDADE SUL-AMERICANA DE NAÇÕES (CSN). Declaración de Margarita: Construyendo la Integración Energética del Sur. Isla de Margarita, 17 de abril de 2007. Disponível em: < http://walk.sela.org/attach/258/EDOCS/SRed/2010/09/To23600002492-0Declaracion de Margarita - Construyendo la integracion energetica del Sur 17 de abril de 2007.pdf $>$. Acesso em 25 de fev. de 2019.

CONSELHO SUL-AMERICANO EM MATÉRIA DE SEGURANÇA CIDADÃ, JUSTIÇA E COORDENAÇÃO DE AÇÕES EM DELINQUÊNCIA ORGANIZADA TRANSNACIONAL (CSSCJDOT). Estatuto del CSSCJDOT. Unasul, 2012.

CORNELL, Agnes, Marcia GRIMES, e Victor LAPUENTE. State Firewalls and Democratic Deepening. Apsa-cd, 2014.

DABÈNE, O. The Politics of Regional Integration in Latin America: Theoretical and Comparative Explorations. Estados Unidos: Palgrave Macmillan, 2009.

DIAMOND, L. Developing democracy: toward consolidation. London: Johns Hopkins University Press. 1999.

DIAMOND, L.J., e MORLINO L. An overview. Journal of democracy 15, nº 4 (2004): 20-31.

FARIA, L.A.E.; TANCREDI, L.M; A Construção da UNASUL: Instituições, Agenda e Interesses. In: $5^{\circ}$ ENCONTRO NACIONAL DA ASSOCIAÇÃO BRASILEIRA DE RELAÇÕES INTERNACIONAIS, anais processos de integração na América Latina. Belo Horizonte: ABRI, 2015.

FARRELL, M. The Global Politics of Regionalism: An Introduction. In: FARRELL, M.; HETTNE, B.; LANGENHOVE, L (Eds.). Global Politics of Regionalism: Theory and Practice. London: Pluto Press, 2005, p. 1-20.

FAWCETT, L. Regionalism from an Historical Perspective. In: FARRELL, M.; HETTNE, B.; LANGENHOVE, L (Eds.). Global Politics of Regionalism: Theory and Practice. London: Pluto Press, 2005, p. 21-37.

FORTI NETO, O. A relação entre Organizações Regionais, consolidação de democracia e segurança cidadã na América Latina: um estudo voltado para o SICA e a UNASUL. 2019. 300p. Tese (Doutorado em Relações Internacionais) - Instituto de Relações Internacionais, Universidade de São Paulo, São Paulo, 2019.

GASKELL, G.; BAUER, M. W. Para uma prestação de contas pública: além da amostra, da fidedignidade e da validade. In: BAUER, M. W.; GASKELL, G. (Ed.). Pesquisa qualitativa com texto, imagem e som: um manual prático. 4. ed. Petrópolis: Vozes, 2005.

GUNTHER, R.; DIAMANDOUROS, P. N.; PUHLE, H. J. O'Donnell's 'Illusions': A Rejoinder. In: PLATTNER, L. D.; MARC, F. The Global Divergence of Democracies, Baltimore and London: The Johns Hopkins University Press, 2001, p. 131-39.

KIRK, J.; MILLER, M. L. Reliability and validity in qualitative research. Thousand Oaks: Sage Publications, 1986.

HEINE, J. Regional Integration and Political Cooperation in Latin America. Latin America Research Review, v.47, n. 3, p.209-17, 2012. 
HURRELL, A. The Regional Dimension in International Relations Theory. In: FARRELL, M.; HETTNE, B.; LANGENHOVE, L (Eds.). Global Politics of Regionalism: Theory and Practice. London: Pluto Press, 2005, p.38-53.

LINZ, J.J; STEPAN, A. Toward Consolidated Democracies. In: DIAMOND, L.; MARC, F. (Eds). The global divergencies of democracies. Baltmore e London: the Johns Hopkins University Press, 2001, p.93-112.

LUIGI, R. A. J. A INTEGRAÇÃO REGIONAL NA AMÉRICA DO SUL: A EFETIVIDADE DA UNIÃO DAS NAÇÕES SUL-AMERICANAS (UNASUL). 2017. 211p. Tese (Doutorado em Geografia). Instituto de Geociência, Universidade de Campinas, São Paulo.

MALAMUD, A. Latin American Regionalism and EU studies. Journal of European Integration, v.32., N.6, p.637-657. 2010.

MALAMUD, A. Overlapping Regionalism, No Integration: Conceptual Issues and the Latin American Experiences. EUI Working Paper Robert Schuman Centre for Advanced Studies, 2013/20. Florencia: European University Institute, 2013.

NERY, T. UNASUL: a dimensão política do novo regionalismo sul-americano. Caderno CRH, v. 29, n. 03, p. 59-75, 2016

MERRIAM, S. Qualitative Research and Case Study Applications in Education. Willey, 1998

MORLINO, L. Qualidades da democracia: como analisá-las. Sociedade e Cultura. V.18, n.2, p.177194. 2015 .

MUNCK, Gerardo. Conceptualizing the quality of democracy: The framing of a new agenda for comparative politics. School of International Relations University of Southern California, 2012, $1-18$.

NOLTE, D. Latin America's New Regional Architecture: A Cooperative or Segmented Regional Governance Complex? SSRN Electronic Journal, n.89, 2014.

NYE, J. Introduction. IN: Nye, J (org). International Regionalism: Readings. Boston: Little, Brown and Company. 1968, p. V-XVI.

O’DONNELL, G. Illusions about Consolidation. In: PLATTNER, L. D.; MARC, F. The Global Divergence of Democracies. Baltimore and London: The Johns Hopkins University Press, 2001, p.113-30.

PROSUL - DECLARAÇÃO DE SANTIAGO. Declaração Presidencial sobre a Renovação e o Fortalecimento da Integração da América do Sul - Santiago, 22 de março de 2019. Disponível em: < http://www.itamaraty.gov.br/pt-BR/notas-a-imprensa/20203-declaracaopresidencial-sobre-a-renovacao-e-o-fortalecimento-da-integracao-da-america-do-sul $>$. Acesso em o9 de abr. 2020.

PROSUL- Declaración de los Mininistros de las Relaciones Exteriores del PROSUR. Nova Iorque, 25 de Setembro de 2019a. Disponível em: <http://www.itamaraty.gov.br/images/ed integracao/docs PROSUL/Declaracin y Lineamiento s PROSUR NY 25-09-2019.pdf >. Acesso em o9 de abr. de 2020.

RIGGIROZZI, P.; TUSSIE, D.(eds.) The Rise of Post-Hegemonic Regionalism: The Case of Latin America. Vol.4. London: Springer, 2012. 
RUVALCABA, D.E.M; VALENCIA, A.R. Construcción de la Unión de Naciones Suramericanas-UNASUR. YUYAYKUSUN, v.5, p. 31-64, 2012.

SCHEDLER, A. What Is Democratic Consolidation? In:PLATTNER, L. D; MARC, F.M. (Eds.). The Global Divergence of Democracies, Baltimore e London: The Johns Hopkins University Press, 2001, p. 149-165.

SERBÍN, A. Atuando Sozinho? Governos, Sociedade civil e Regionalismo na América do Sul. Lua Nova, n.90, p.297-327, 2013.

SLOVIK, M. "Which Democracies Will Last? Coups, Incumbent, Takeover, and the Dinamic of Democratic Consolidation.” British Journal of Political Science 45 (2014): 1-24.

UNIÃO DAS NAÇÕES SUL-AMERICANAS (UNASUL). Tratado Constitutivo de la Unión de Naciones Suramericanas. Quito: Unasul, 2008.

UNIÃO DAS NAÇÕES SUL-AMERICANAS (UNASUL). Protocolo Adicional ao Tratado Constitutivo da Unasul sobre Compromisso com a Democracia. Georgetown: Unasul, 2010.

VENNESSON, P. Case studies and process tracing: theories and practices. In: PORTA, D.; KEATING, M. (Eds.) Approaches and Methodologies in the Social Sciences: A Pluralist Perspective. Cambridge: Cambridge University Press, 2008, p.223-239.

YIN, R. K. Case study research: design and methods. Thousand Oaks; London; New Delhi: Sage Publications, 2015.

\section{ENTREVISTAS}

- Embaixador do MRE do Uruguai. 2018.

- Diretor da Unidade de Segurança Cidadã da UNASUL. 2018.

- Coordenador-Geral de Combate a Ilícitos Transnacionais (COCIT) do MRE do Brasil. 2018.

- Assessora da Direção Nacional de Assuntos Internacionais do Ministérios da Justiça e Direitos Humanos da Argentina. 2019.

- Servidor Público do Ministério da Justiça e Direitos Humanos (MINJUSDH), coordenador conselheiro de defesa jurídica do Estado do Peru. 2018.

- Funcionário de carreira diplomática e consular da Colômbia como conselheiro. 2018.

- Servidor público - Ministério do Planejamento - Advocacia da União. Instituto brasileiro de Ciências Criminais. Também participou do ministério da Justiça. 2018.

- Embaixador do Peru. 2018.

- Oficial do MRE do Peru. 2018.

- Oficial do MRE da Guiana. 2019. 